LA W RENCE LIVERMORE N A TIO N A L LABORATORY
Procedures for Db chemical characterization in off-line experiments

E. E. Tereshatov, J. M. Gostic, R. A. Henderson, D. A. Shaughnessy, K. J. Moody

December 7, 2011

Journal of Radioanalytical and Nuclear Chemistry 
This document was prepared as an account of work sponsored by an agency of the United States government. Neither the United States government nor Lawrence Livermore National Security, LLC, nor any of their employees makes any warranty, expressed or implied, or assumes any legal liability or responsibility for the accuracy, completeness, or usefulness of any information, apparatus, product, or process disclosed, or represents that its use would not infringe privately owned rights. Reference herein to any specific commercial product, process, or service by trade name, trademark, manufacturer, or otherwise does not necessarily constitute or imply its endorsement, recommendation, or favoring by the United States government or Lawrence Livermore National Security, LLC. The views and opinions of authors expressed herein do not necessarily state or reflect those of the United States government or Lawrence Livermore National Security, LLC, and shall not be used for advertising or product endorsement purposes. 


\title{
Procedures for Db chemical characterization in off-line experiments
}

\author{
Tereshatov E.E., Gostic J.M., Henderson R.A., Shaughnessy D.A., and Moody K.J.
}

Lawrence Livermore National Laboratory, Livermore, CA, 94550

\begin{abstract}
A new procedure to isolate carrier-free isotopes of $\mathrm{Nb}$ and $\mathrm{Ta}$ after a $12-\mathrm{MeV}$ proton bombardment of a natural Hf foil has been considered. The cross section of the corresponding ${ }^{\text {nat }} \mathrm{Hf}(\mathrm{p}, \mathrm{x})^{179} \mathrm{Ta}$ reaction has been estimated for the first time as $5.4 \pm 0.5 \mathrm{mb}$. The isotopes that were produced were subsequently used for development of procedures for the chemical characterization of element $105(\mathrm{Db})$. $\mathrm{HF} / \mathrm{HNO}_{3}$ and $\mathrm{HNO}_{3} / \mathrm{H}_{2} \mathrm{O}_{2}$ media have been chosen and the parameters of the experiments have been optimized. Based on the results obtained in this work, offline experimental procedures have been proposed for the evaluation of the chemical behavior of $\mathrm{Db}$.
\end{abstract}

\section{Introduction}

The discovery and investigation of superheavy elements (SHE) are difficult due to the very low production cross sections of these new nuclides, at the level of several picobarns. This results in the detection of about 1 atom per day or even more infrequently. The particular type of nuclear reaction used to produce these nuclides determines the magnitude of the cross section, which is a function of the combination of target and projectile nuclides. So called "warm" fusion reactions have played a significant role in the discovery and study of elements beyond 112 (Cn). In this reaction doubly magic ${ }^{48} \mathrm{Ca}$ ions are used to bombard actinide targets. This approach was successfully implemented to synthesize SHE $113-118$ and to characterize the parent nuclei and their descendant nuclides. It should be noted that decay chains of odd-Z elements in the vicinity of the Island of Stability [1] consist 
of several sequential alpha-decays terminated by spontaneous fission (SF), mostly of $\mathrm{Db}$ isotopes. The only exception that has been observed so far is the decay of ${ }^{293} 117$, which leads to the SF of ${ }^{281} \operatorname{Rg}$ [2]. ${ }^{268} \mathrm{Db}$ was reported as part of the ${ }^{288} 115$ decay chain with a half-life of about 1 day $[3,4]$. This nuclide is sufficiently longlived that the dubnium can be chemically characterized. The ${ }^{243} \mathrm{Am}+{ }^{48} \mathrm{Ca}$ reaction is therefore a method for both the synthesis of elements 115 and 113 and for studying the chemical behavior of $\mathrm{Db}$.

Two experiments devoted to the identification of elements 115 and 113 via registration of $\mathrm{Db} \mathrm{SF}$ fragments have been reported in the literature $[5,6]$. The procedures were based on isolation of Group $\mathrm{V}$ elements from an initial matrix using $\mathrm{La}(\mathrm{OH})_{3}$ precipitation followed by ion exchange or reversed-phase chromatography $[7,8]$. The precipitation is required to remove the bulk of the copper catcher material, to remove the Group VI - XIV elements, and to concentrate the elements of interest in the precipitate. Cation exchange was subsequently used to isolate the Group V elements from the trivalent actinides produced both from the recoil of target material and as transfer-reaction products. During this experiment $15 \mathrm{SF}$ events were detected that could be attributed to decay products of ${ }^{288} 115$ based on long-term spectrometric analysis of a final sample [9]. Within a second experiment designed to isolate $\mathrm{Db}$, a $\mathrm{LaF}_{3}$ precipitation followed by either anion or extraction chromatography was used instead of cation exchange. In that experiment the isolation of the Group $\mathrm{V}$ elements was followed by the separation of $\mathrm{Nb}$ and $\mathrm{Ta}$ into separate fractions in order to characterize $\mathrm{Db}$ chemical properties. An additional 5 more SF events were detected, 2 in the Group $\mathrm{V}$ fractions and 3 in the Ta fractions, and the observed fission events might be considered as decay of element 105 [10]. Since two different chemical solutions were used to elute dubnium homologues it cannot be absolutely determined whether or not $\mathrm{Db}$ exhibited Ta-like behavior. The only 
conclusion that might be drawn is that the Db distribution coefficient under the given experimental conditions was higher than that of $\mathrm{Nb}$. Pa-like behavior of $\mathrm{Db}$ could also be dismissed because $\mathrm{Pa}$ would have co-precipitated with the $\mathrm{LaF}_{3}$. The radiochemical yields of Groups III $-\mathrm{V}$ and VII elements in the experiments mentioned above are given in Table 1. It can be seen that the average yields of the Group V elements are about $80 \%$ and that the scandium activity in the second experiment is two orders of magnitude lower than in the first one.

Table 1

Average yields of radionuclides, in $\%$, for the indicated experiments (see text)

\begin{tabular}{|c|c|c|c|c|c|c|}
\hline \multirow{2}{*}{ Isotope } & Experiment I & \multicolumn{6}{|c|}{ Experiment II } \\
\cline { 2 - 7 } & IV/V-fraction & LaF $_{\mathbf{3}}$ & $\mathbf{I V}^{\mathrm{IV}}$-fraction & V-fraction & Nb-fraction & Ta-fraction \\
\hline $\mathrm{Nb}-92 \mathrm{~m}$ & $80 \pm 2$ & $1.0 \pm 0.3^{\mathrm{a}}$ & $0.26 \pm 0.04^{\mathrm{a}}$ & $86 \pm 6$ & $84 \pm 2$ & $0.11 \pm 0.04$ \\
\hline $\mathrm{Ta}-177$ & $57 \pm 19$ & - & - & $93 \pm 7$ & - & $83 \pm 5$ \\
\hline $\mathrm{Hf}-175$ & $64 \pm 2$ & - & $56 \pm 4$ & $1.70 \pm 0.06$ & - & $0.08 \pm 0.01$ \\
\hline $\mathrm{Zr}-89$ & $53 \pm 3$ & $68 \pm 4$ & $52 \pm 2$ & $0.48 \pm 0.10$ & $0.41 \pm 0.06$ & $0.07 \pm 0.02$ \\
\hline $\mathrm{Sc}-48$ & $43.7 \pm 1.2$ & $75 \pm 2$ & $0.08 \pm 0.02^{\mathrm{b}}$ & $0.14 \pm 0.02$ & $0.07 \pm 0.02$ & - \\
\hline $\mathrm{Y}-87$ & $0.74 \pm 0.07$ & $75 \pm 2$ & $0.38 \pm 0.02$ & $0.47 \pm 0.03$ & - & $0.06 \pm 0.01$ \\
\hline $\mathrm{Rh}-102 \mathrm{~m}$ & $5.2 \pm 0.7^{\mathrm{c}}$ & $4.4 \pm 0.3^{\mathrm{c}}$ & $0.10 \pm 0.01$ & $0.06 \pm 0.01$ & $0.22 \pm 0.01$ & $0.04 \pm 0.01$ \\
\hline
\end{tabular}

$\mathrm{a}-$ data for Nb-90 $\quad \mathrm{b}-$ data for Sc-46 $\quad \mathrm{c}-$ data for $\mathrm{Rh}-101 \mathrm{~m}$

There were some disadvantages with these two procedures. In the first case, by-products such as isotopes of $\mathrm{Zr}, \mathrm{Sc}$, and $\mathrm{Rh}$ did not allow for immediate $\alpha$ measurements of the prepared samples because of high $\beta$-activity. Moreover, the Group V elements were eluted along with the Group IV elements; therefore, spontaneous fission events might be attributed to ${ }^{268} \mathrm{Rf}$ produced via the ${ }^{243} \mathrm{Am}\left({ }^{48} \mathrm{Ca}, 3 \mathrm{n}\right){ }^{288} 115 \longrightarrow{ }^{5 \alpha} \longrightarrow{ }^{268} \mathrm{Db} \stackrel{\text { E.C. }}{\longrightarrow}{ }^{268} \mathrm{Rf}$ reaction, which has to be taken into account when confirming the original synthesis of elements 115 and 113 . Additionally, the probability of the ${ }^{243} \mathrm{Am}\left({ }^{48} \mathrm{Ca}, \mathrm{pxn}\right){ }^{290-\mathrm{x}} 114$ reaction occurring is very low [11], which likely excludes direct production of element 114 and its daughters. The observed results were in good agreement with expectations from the previously reported decay chains of element 115 produced at the Dubna Gas- 
Filled Recoil Separator (DGFRS) [3]. In order to check an assumption that dubnium undergoes electron capture prior to the SF, separation of Group IV and V elements is required, which was the motivation for performing the second experiment. In terms of purification from actinides, $\mathrm{LaF}_{3}$ precipitation might not be as efficient as the cation-exchange step. Moreover, an extra chemical step is needed to extract the Group IV elements from the lanthanum fluoride precipitate.

The goal of this work is to develop a relatively simple and fast procedure in order to characterize dubnium as a decay chain product of the decays of elements 115 and 113. As described above, a separation between Group IV and V elements is required.

\section{Experimental}

Carrier-free tracers of $\mathrm{Nb}$ and $\mathrm{Ta}$ radionuclides were produced by bombarding a metal ${ }^{\text {nat }} \mathrm{Hf}$ foil of $1.15 \mathrm{~g}$ and $99 \%$ purity at the $1 \mathrm{MV}$ Tandem accelerator at the Center for Accelerator Mass Spectrometry (CAMS) at Lawrence Livermore National Laboratory (LLNL). The foil was irradiated for $10.5 \mathrm{~h}$ with $12 \mathrm{MeV}$ protons on target at a current of $100-400 \mathrm{nA}$. After irradiation the foil was allowed to cool for 4.5 days and was then dissolved in conc. $\mathrm{HNO}_{3}$ with several drops of conc. HF. The resulting solution was evaporated to dryness and reconstituted in a $6 \mathrm{M} \mathrm{HF} / 4 \mathrm{M} \mathrm{HCl}$ matrix. The solution was loaded onto a 4x80 mm column of Dowex 1x4, -400 mesh resin that had been pretreated with the same acid mixture. The Hf was eluted from the column with $3 \mathrm{~mL}$ of $6 \mathrm{M} \mathrm{HF} / 4 \mathrm{M} \mathrm{HCl}$ while the Group $\mathrm{V}$ elements were retained on the resin. $\mathrm{Nb}$ and $\mathrm{Ta}$ were then eluted from the column with $20 \mathrm{~mL}$ of $6 \mathrm{M} \mathrm{HF} / 4 \mathrm{M} \mathrm{HCl}$ and $10 \mathrm{~mL}$ of $6 \mathrm{M} \mathrm{HF} / 4$ $\mathrm{MHNO}_{3}$ respectively. The fractions were evaporated to dryness and reconstituted in $1 \mathrm{M} \mathrm{HF}$ prior to the model study. 
Hf-175 was produced by irradiating a ${ }^{\text {nat }} \mathrm{Lu}$ foil for 12 hours with $12-14 \mathrm{MeV}$ protons on target at CAMS. The Lu foil was dissolved in aqua regia. The solution was taken to dryness, then re-dissolved in conc. $\mathrm{HCl}$ and loaded onto a $4 \times 40 \mathrm{~mm}$ column of AG 1X8, 100-200 mesh that had been pretreated with conc. HCl. About $30 \mathrm{~mL}$ of conc. $\mathrm{HCl}$ was passed through the column to remove Lu. The $\mathrm{Hf}$ was then eluted with $15 \mathrm{~mL}$ of $6 \mathrm{M} \mathrm{HCl}$. The $\mathrm{Hf}$ was taken to dryness, and the procedure repeated.

The anion exchangers used for the separation studies were all in the $\mathrm{Cl}^{-}$-form and included AG 1x8, 100-200 mesh, Dowex 1x8, 200-400 mesh and Dowex 1x4, -400 mesh. The constant flow rate of eluents was chosen to be $0.25 \mathrm{~mL} \mathrm{~min}{ }^{-1}$. A standard High Purity Ge-detector with associated Maestro software was used to determine an activity level of each isotope in the samples.

\section{Results and Discussions}

Production cross sections for proton-induced reactions in natural $\mathrm{Hf}$ are given

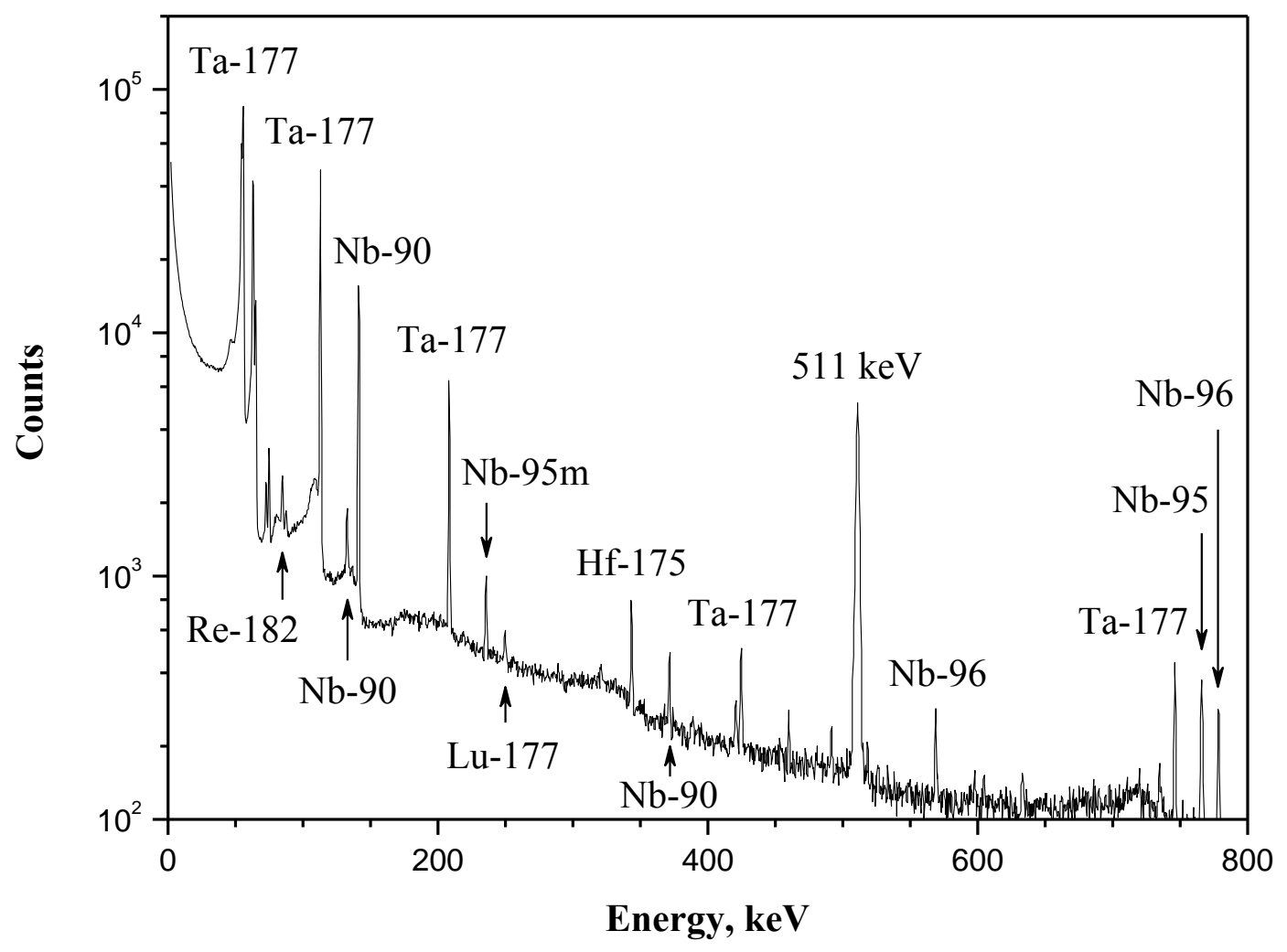

Fig. 1. Gamma-spectrum of an aliquot of dissolved $\mathrm{Hf}$ foil post-irradiation $(\mathrm{Nb}-92 \mathrm{~m}$ is also present but isn't shown) 
in Ref. [12]. The largest reported cross section is that of ${ }^{177} \mathrm{Ta}$, which is the longestlived Ta isotope considered in the paper. Under our experimental conditions we expected a cross section of $155 \pm 13 \mathrm{mb}$ for the ${ }^{\text {nat }} \mathrm{Hf}(\mathrm{p}, \mathrm{x}){ }^{177} \mathrm{Ta}$ reaction. This value is in good agreement with the reported calculated value of $135 \mathrm{mb}$ for the ${ }^{177} \mathrm{Hf}(\mathrm{p}, \mathrm{n}){ }^{177} \mathrm{Ta}$ reaction [13], which is considered to be the primary reaction channel.

Figure 1 shows the gamma spectrum of an aliquot of the initial solution produced through dissolution of the irradiated $\mathrm{Hf}$ foil. Based on the resulting gamma spectrum, it was evident that the foil also contained ${ }^{\text {nat }} \mathrm{Zr}$ and ${ }^{\text {nat }} \mathrm{W}$ impurities. Proton irradiation of these elements leads to the production of a number of $\mathrm{Nb}[14-16]$ and $\operatorname{Re}[17]$ isotopes. Literature data indicate that under the given experimental conditions, the cross section observed for production of ${ }^{90} \mathrm{Nb}$ might be at least twice that of ${ }^{177} \mathrm{Ta}$; therefore, detectable carrier-free amounts of other Group V elements might also be synthesized via proton irradiation of the Hf foil.

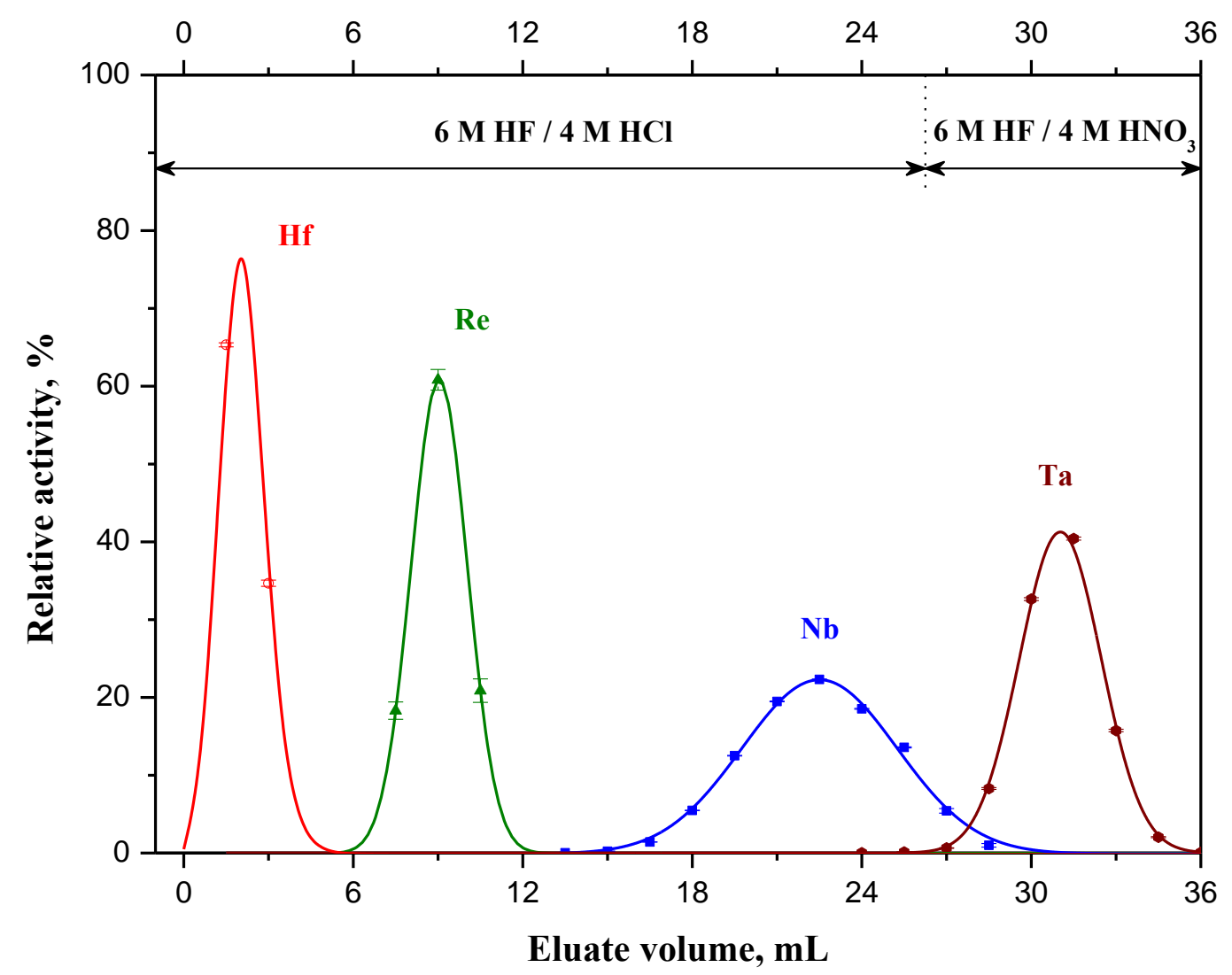

Fig. 2. Separation of $\mathrm{Hf}, \mathrm{Re}, \mathrm{Nb}$ and $\mathrm{Ta}$ on a $4 \times 80 \mathrm{~mm}$ anion exchange column with Dowex 1x4, 400 mesh resin 
The procedure used for isolation of niobium and tantalum from the irradiated Hf foil was based on the results reported in Ref. [18]. Figure 2 shows that in the 6 $\mathrm{M} \mathrm{HF} / 4 \mathrm{M} \mathrm{HCl}$ medium isocratic separation of $\mathrm{Hf}, \mathrm{Re}$, and $\mathrm{Nb}$ was successfully achieved and was in good agreement with the data reported in Refs. [19, 20]. The gamma spectrum of the Re fraction is shown in Figure 3.

Further analysis of the Ta fraction reveals the presence of ${ }^{179} \mathrm{Ta}$, which was detectable only after the ${ }^{175-178}$ Ta decayed out. There are no gamma lines associated with ${ }^{179}$ Ta decay, so only the Hf X-ray photons could be used for detection [21]. Through detection of the X-rays, the ${ }^{179} \mathrm{Ta}$ cross section from the ${ }^{\text {nat }} \mathrm{Hf}(\mathrm{p}, \mathrm{x}){ }^{179} \mathrm{Ta}$ reaction was estimated to be $5.4 \pm 0.5 \mathrm{mb}$. The given cross section estimate was based on the ratio of the ${ }^{177} \mathrm{Ta}$ and ${ }^{179} \mathrm{Ta}$ activities, which took the time since the end of bombardment and the known cross section of ${ }^{177} \mathrm{Ta}$ into account [12]. Figure 4 reflects excitation functions for the reactions ${ }^{\text {nat }} \mathrm{Hf}(\mathrm{p}, \mathrm{x}){ }^{175-179} \mathrm{Ta}$ as a function of proton energy and includes our measurement of ${ }^{179}$ Ta production at $12 \mathrm{MeV}$.

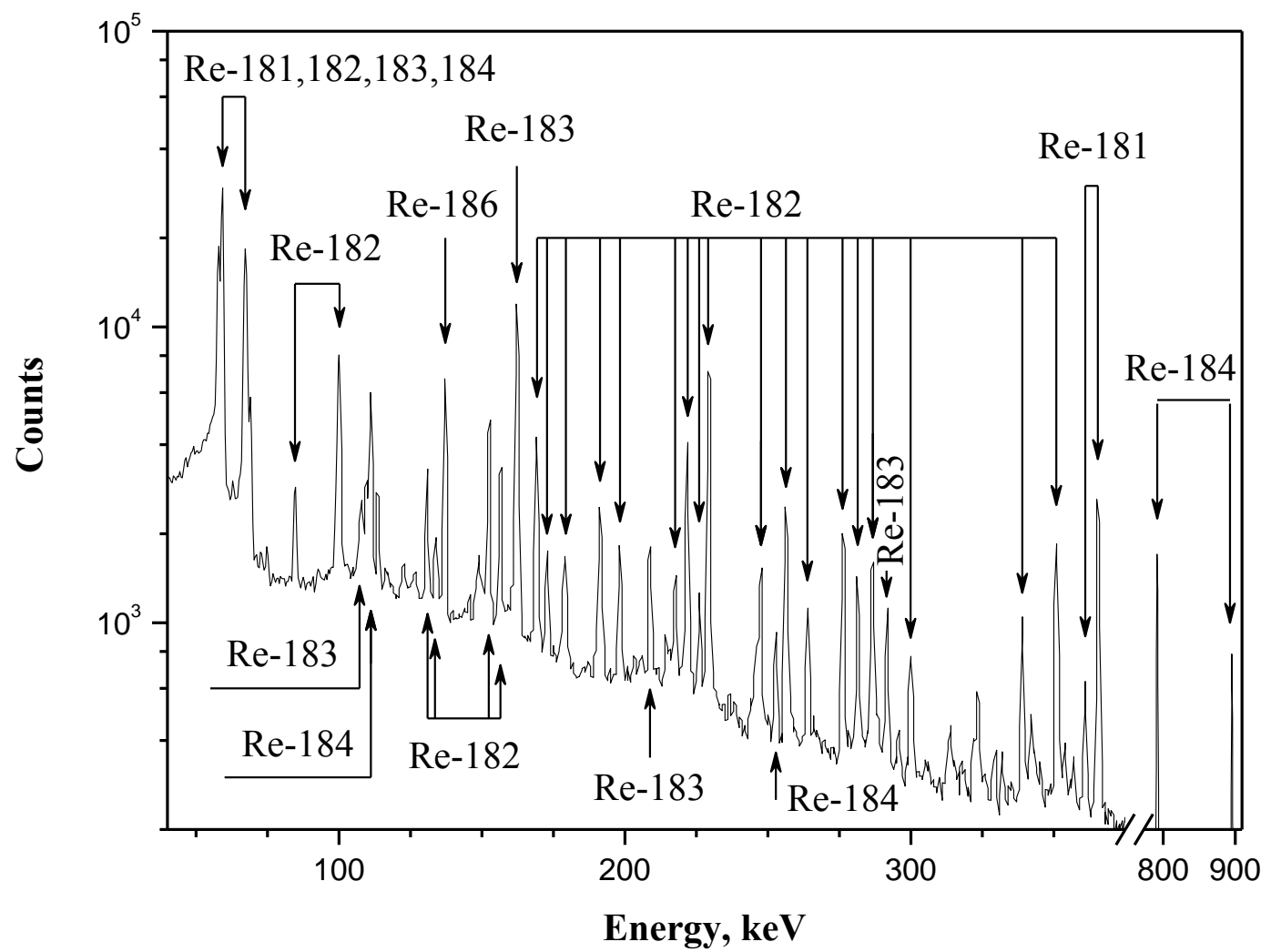

Fig. 3. Gamma-spectrum of Re-fraction 


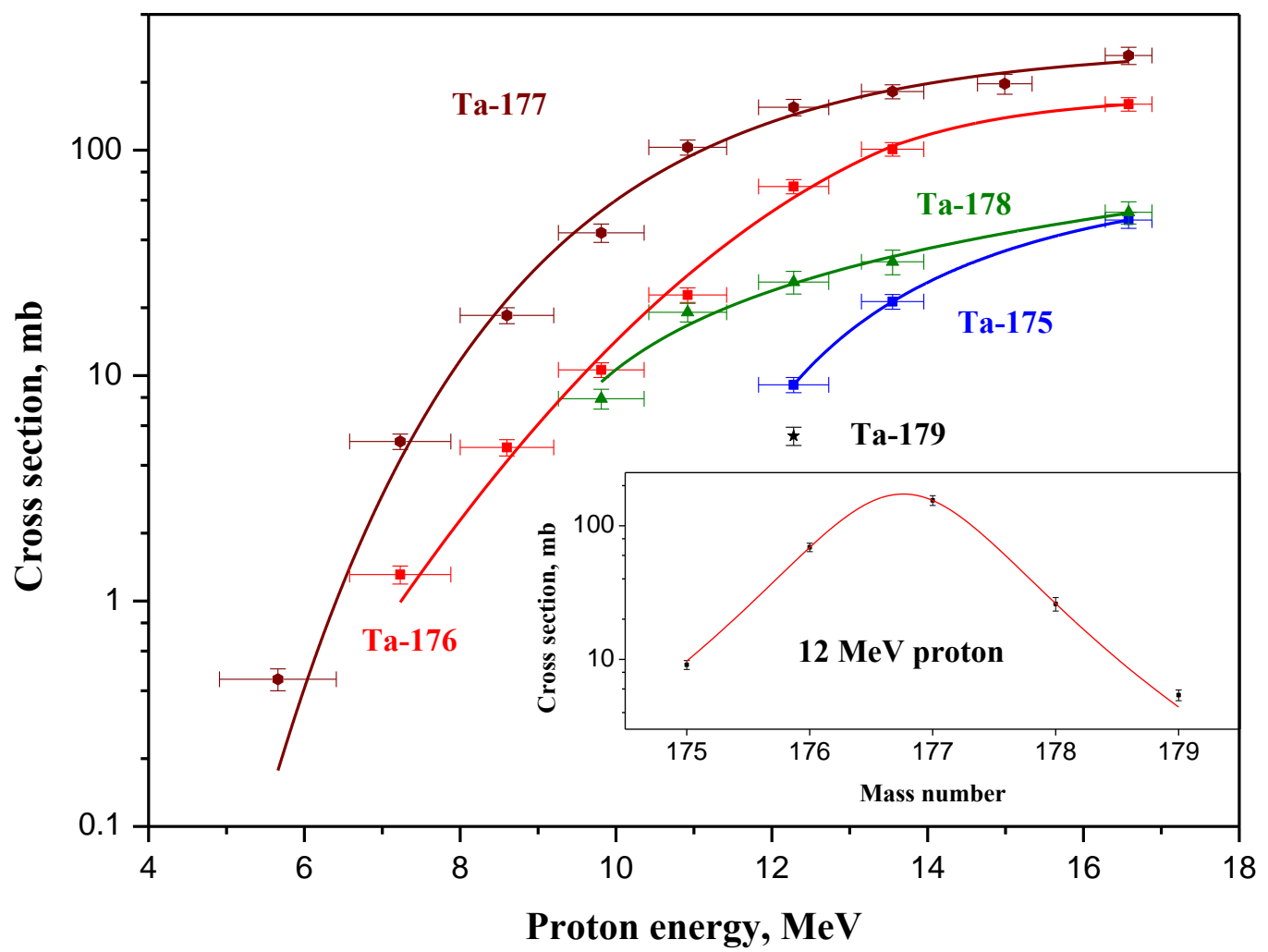

Fig. 4. Cross section of the reaction ${ }^{\mathrm{nat}} \mathrm{Hf}(\mathrm{p}, \mathrm{x}){ }^{175-179} \mathrm{Ta}$ (data for ${ }^{175-178} \mathrm{Ta}$ are from Ref. [12])

Chemical characterization of $\mathrm{Db}$ starts with the isolation of $\mathrm{Nb}$ and $\mathrm{Ta}$ together via separation from Group IV elements. In order to obtain a large total efficiency for an experiment the separation factor between Group IV and V elements must be as high as possible while minimizing the volume of each fraction in order to facilitate the fast preparation of a counting sample. Based on reported data of distribution coefficients $\left(\mathrm{K}_{\mathrm{d}}\right)[18,22]$ for the elements mentioned above in $\mathrm{HF} / \mathrm{HNO}_{3}$ media, the $11 \mathrm{M} \mathrm{HF} / 7.7 \mathrm{M} \mathrm{HNO}_{3}$ matrix was chosen to achieve the goal of separating the Group IV elements from a combined $\mathrm{Nb}$ and Ta fraction. Under these conditions the $K_{d}$ values of $\mathrm{Nb}$ and Ta are relatively small and close to each other, which allows them to be eluted together in a small fractional volume. Distribution coefficients of Group IV elements are always less than those of $\mathrm{Nb}$ and Ta under considered conditions, so $\mathrm{Hf}$ and $\mathrm{Zr}$ will be eluted from the column in a fraction before the Group V elements. 


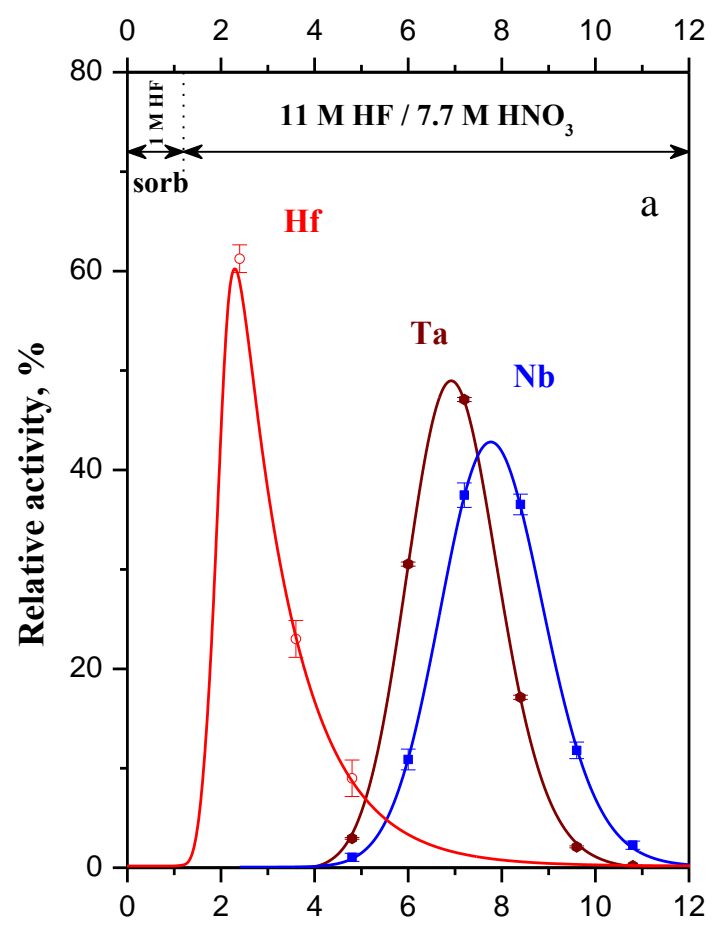

Eluate volume, $\mathbf{m L}$

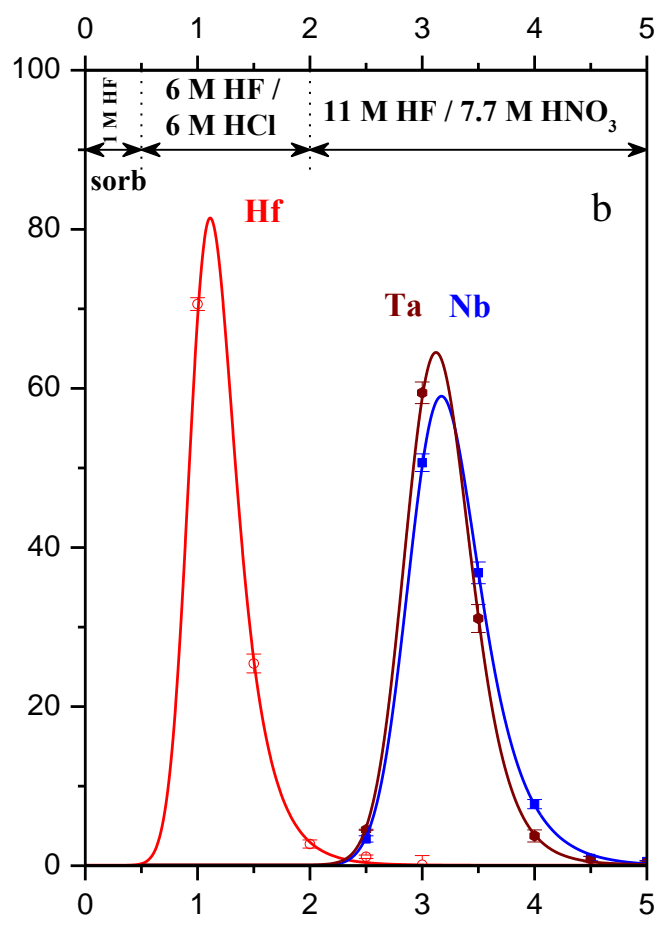

Eluate volume, $\mathbf{m L}$

Fig. 5. Separation of $\mathrm{Hf}, \mathrm{Nb}$ and $\mathrm{Ta}$ : a - AG 1x8, 100-200 mesh, 4.7x57 mm, b - Dowex 1x4, -400 mesh, 4x16 mm

Figure 5 shows the resulting $\mathrm{Hf}$ and $\mathrm{Nb} / \mathrm{Ta}$ elution curves. One can see that niobium and tantalum were eluted together and there is an isocratic separation of the Group IV and V elements (Fig. 5a). In order to reduce eluant fraction volumes, Dowex 1x4, -400 mesh resin and a smaller column size were used. Also, a stepwise elution was applied to decrease the overlap between the Group IV and V elution peaks. The Hf was eluted in a $1.5 \mathrm{~mL}$ fraction and the $\mathrm{Nb} / \mathrm{Ta}$ fraction was eluted in about $3 \mathrm{~mL}$.

Unfortunately, the $11 \mathrm{M} \mathrm{HF/7.7} \mathrm{M} \mathrm{HNO}_{3}$ matrix is highly aggressive and destroys the anion exchange resin almost immediately. One can see this by coloration of the eluate. While evaporating these fractions, organic residues might therefore be expected to be present on the sample surface, leading to possible deterioration of the alpha-spectra resolution and loss of fission-fragment energy. In order to optimize separation of the Group IV and $\mathrm{V}$ elements another $\mathrm{HF} / \mathrm{HNO}_{3}$ 
acid concentration ratio was considered. Analysis of 3D diagrams of $\mathrm{Nb}$ and $\mathrm{Ta}$ distribution coefficients [18] indicates several concentration regions where the $K_{d}$ values are close to each other and relatively small. Among these the region of the least concentrated acids has been chosen. Figure 6 depicts $\mathrm{Nb} / \mathrm{Ta}$ elution curves using $8 \mathrm{M} \mathrm{HF} / 3 \mathrm{M} \mathrm{HNO}_{3}$.

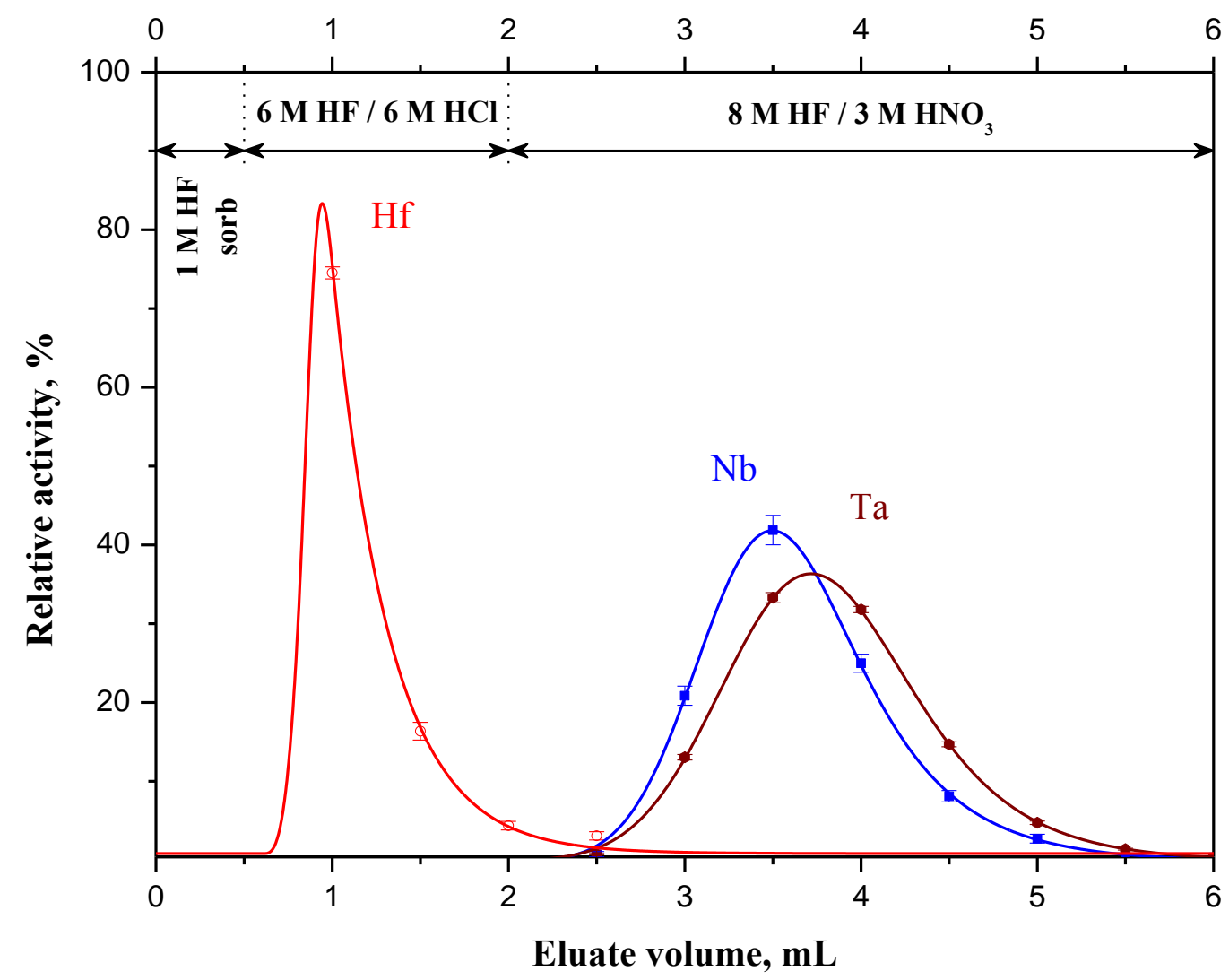

Fig. 6. Separation of $\mathrm{Hf}, \mathrm{Nb}$ and $\mathrm{Ta}$ on $4 \times 12 \mathrm{~mm}$ column with Dowex $1 \mathrm{x} 4,-400$ mesh resin

It is well known that $\mathrm{Nb}$ forms pure fluoride complexes only at $[\mathrm{HF}]>10 \mathrm{M}$ [23]. This is the main reason why $\mathrm{Nb}$ elutes after Ta under these conditions. At lower HF concentrations, formation of $\left[\mathrm{NbOF}_{n}\right]^{3-\mathrm{n}}$ and $\left[\mathrm{Nb}(\mathrm{OH})_{2} \mathrm{~F}_{n}\right]^{3-\mathrm{n}}$ species should be considered and the elution order of $\mathrm{Nb}$ and Ta will be changed. Figure 6 shows that $\mathrm{Nb}$ and $\mathrm{Ta}$ were eluted together and their $\mathrm{K}_{\mathrm{d}}$ values were estimated correctly. Despite the fact that the volume of the fraction containing the Group V elements was slightly larger than what is shown on Fig. 5b, this matrix might be preferred for this separation because there is no noticeable anion-exchange resin 
destruction and the last mL eluted from the column contained only about $1 \%$ of the total activity of each element.

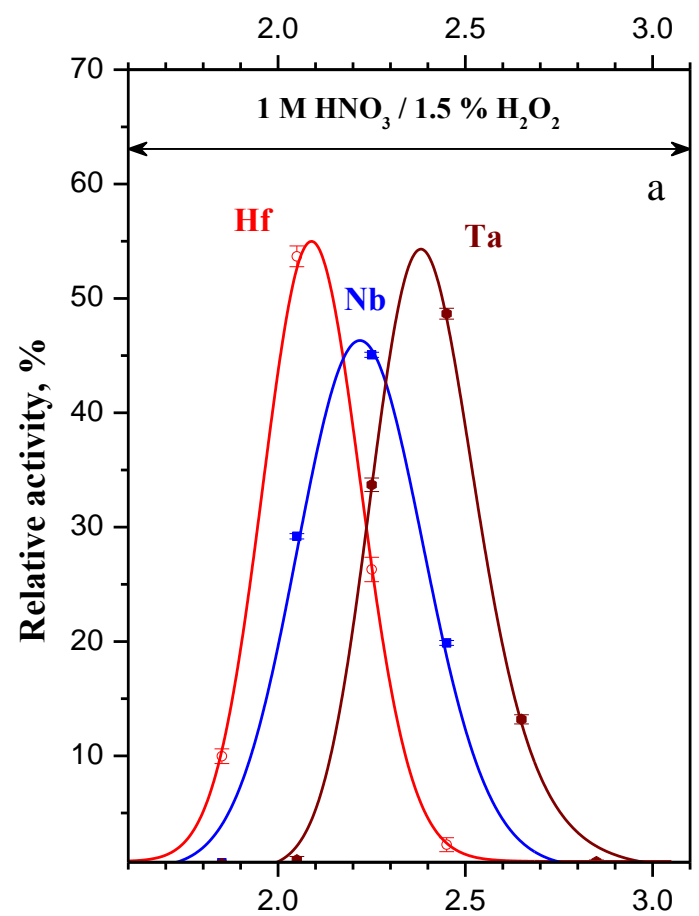

Eluate volume, $\mathbf{m L}$

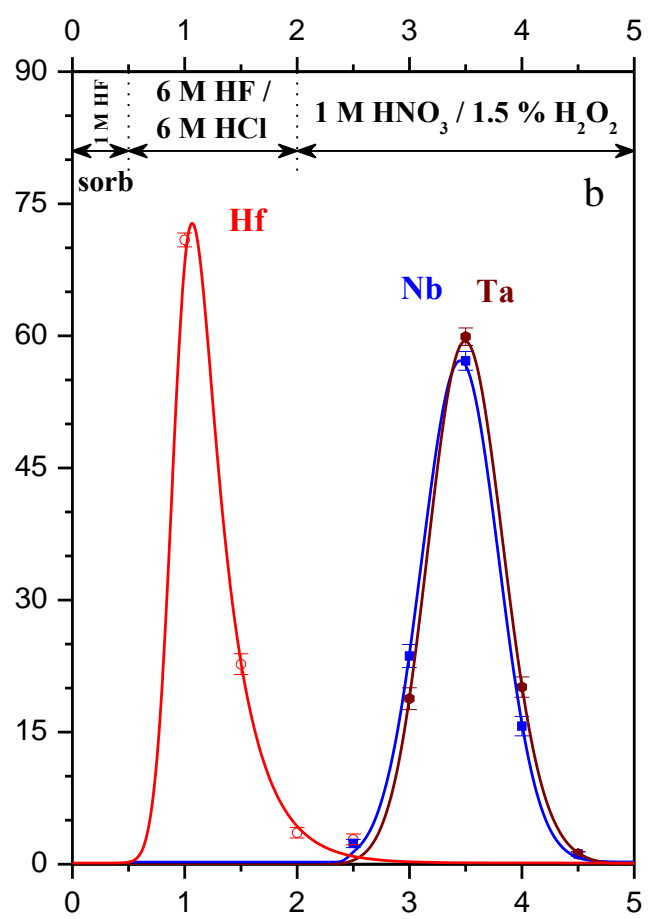

Eluate volume, $\mathbf{m L}$

Fig. 7. Separation of $\mathrm{Hf}, \mathrm{Nb}$ and $\mathrm{Ta}$ : a-Dowex 1x8, 200-400 mesh, 6x10 mm, b - Dowex 1x4, -400 mesh, 4x16 mm

Distribution coefficients for $\mathrm{Ta}$ on anion-exchange resin in $\mathrm{HF}$ media are extremely high, which is why a nitric acid and hydrogen peroxide mixture is widely used to desorb it $[24,25]$. Such an approach was applied in the experimental study of $\mathrm{Db}$ behavior [6] at the Flerov Laboratory for Nuclear Reactions (FLNR). Under these conditions Group V elements might be eluted simultaneously with the Group IV elements if preliminary chemical separations have not been implemented. Figure 7 reflects the behavior of $\mathrm{Hf}, \mathrm{Nb}$ and $\mathrm{Ta}$ in a mixture of $1 \mathrm{M} \mathrm{HNO}_{3} / 1.5 \% \mathrm{H}_{2} \mathrm{O}_{2}$. Stepwise elution was again employed to separate $\mathrm{Hf}$ from $\mathrm{Nb} / \mathrm{Ta}$ (Fig. 7b). The volume of each fraction was equal to those shown in Fig. 5b. Therefore, two independent chemical systems have been 
developed for the investigation of the chemical properties of $\mathrm{Db}$ and its homologues.

The procedure for the entire chemical process for separation of any SHE liquid-phase study should include the following steps: collection of recoil atoms, removal of bulk amounts of the catcher material, separation and purification of the elements of interest, and final source preparation.

Two Db off-line experiments that have been discussed in the literature used $\mathrm{Cu}$ catchers where the recoiling reaction-product atoms were implanted into the surface layers of a $\mathrm{Cu}$ block. Lanthanum hydroxide precipitation was successfully employed to remove copper and Group VI - XIV elements and concentrate the Group III - V elements in the solid phase [7]. Afterwards a cation-exchange step with $1 \mathrm{M} \mathrm{HF}$ as the eluent was required to isolate trivalent lanthanides and actinides [26] from the Group IV and V elements. In Ref. [27] it was shown that $\mathrm{Zr}, \mathrm{Hf}, \mathrm{Nb}$ and $\mathrm{Ta}$ release from cation-exchange resin $\left(\mathrm{K}_{\mathrm{d}}<2\right)$ with eluant concentrations < $1 \mathrm{M} \mathrm{HF}$, whereas alkaline, alkaline-earth and rare-earth elements remain on the resin. The eluant from the cation-exchange step is then loaded onto an anion-exchange column. The elements of interest in this system have sufficiently high $\mathrm{K}_{\mathrm{d}}$ values to be adsorbed on Dowex 1x4 resin, but these values increase about 1.5-2 times for adsorption on Dowex 1x8 resin [28]. Choosing the anion-exchange procedures described in this paper to separate Group IV and V elements will result in a minimum number of chemical steps before preparation of a final counting source for measurement and an increase of yield. Moreover, it will help to reduce the time required to carry out the experiment and make it possible to automate the procedure. 


\section{Conclusion}

Dowex $1 \mathrm{x} 4$ resin has been used to isolate $\mathrm{Nb}$ and $\mathrm{Ta}$ isotopes as part of a procedure to purify an irradiated Hf foil and for procedure development for future investigations of the chemical properties of $\mathrm{Db}$. The procedure to separate Group $\mathrm{V}$ elements from macro amounts of Hf was successfully used for the isocratic anion exchange separation of $\mathrm{Hf}, \mathrm{Re}$ and $\mathrm{Nb}$. Analysis of the photons emitted by the Tafraction allowed us to estimate the production cross section of the $12 \mathrm{MeV}$ proton induced reaction ${ }^{\text {nat }} \mathrm{Hf}(\mathrm{p}, \mathrm{x}){ }^{179} \mathrm{Ta}$ at a value of $5.4 \pm 0.5 \mathrm{mb}$.

Several procedures have been considered for the separation of Group IV from Group V elements. $\mathrm{HF} / \mathrm{HNO}_{3}$ and $\mathrm{HNO}_{3} / \mathrm{H}_{2} \mathrm{O}_{2}$ media have been used to achieve the final goal. $11 \mathrm{MHF} / 7.7 \mathrm{M} \mathrm{HNO}_{3}$ and $1 \mathrm{M} \mathrm{HNO}_{3} / 1.5 \% \mathrm{H}_{2} \mathrm{O}_{2}$ solutions show almost identical elution curves of $\mathrm{Hf}, \mathrm{Nb}$ and $\mathrm{Ta}$. Under the first set of conditions destruction of the resin might be observed and an alternative $8 \mathrm{M} \mathrm{HF} / 3 \mathrm{M} \mathrm{HNO}_{3}$ mixture has been implemented. This leads to a slight increase of the fraction volume of the Group V elements.

A combination of consecutive steps comprising an off-line experiment to measure the chemical properties of $\mathrm{Db}$ has been suggested. Lanthanum hydroxide precipitation is a well known matrix to remove copper and Group VI - XIV elements after irradiation. The next step is to use a cation-exchange resin column to separate Group IV and V elements from Group I - III elements. Two parallel anion-exchange procedures have been proposed to quickly separate Group IV and $\mathrm{V}$ elements. Therefore, a new off-line experiment might be carried out to

chemically characterize $\mathrm{Db}$ properties in order to both independently confirm the synthesis of elements 115 and 113 and study dubnium chemical behavior. 


\section{Acknowledgements}

The authors would like to thank the CAMS facility staff at LLNL for providing beam time and expertise to the production of radionuclides used in this study.

This work was performed under the auspices of the U.S. Department of Energy by Lawrence Livermore National Laboratory under Contract DE-AC5207NA27344. This work was funded by the Laboratory Directed Research and Development Program at LLNL under project tracking code 11-ERD-011.

\section{References}

1. Oganessian, Yu. Ts.: Synthesis of the heaviest elements in ${ }^{48} \mathrm{Ca}$-induced reactions. Radiochim. Acta 99, 429 (2011).

2. Oganessian, Yu. Ts., Abdullin, F. Sh., Bailey, P. D., Benker, D. E., Bennett, M. E., Dmitriev, S. N., Ezold, J. G., Hamilton, J. H., Henderson, R. A., Itkis, M. G., Lobanov, Yu. V., Mezentsev, A. N., Moody, K. J., Nelson, S. L., Polyakov, A. N., Porter, C. E., Ramayya, A. V., Riley, F. D., Roberto, J. B., Ryabinin, M. A., Rykaczewski, K. P., Sagaidak, R. N., Shaughnessy, D. A., Shirokovsky, I. V., Stoyer, M. A., Subbotin, V. G., Sudowe, R., Sukhov, A. M., Taylor, R., Tsyganov, Yu. S., Utyonkov, V. K., Voinov, A. A., Vostokin, G. K., and Wilk, P. A.: Eleven new heaviest isotopes of elements $Z=105$ to $Z=117$ identified among the products of ${ }^{249} \mathrm{Bk}+{ }^{48} \mathrm{Ca}$ reactions. Phys. Rev. C 83, 054315 (2011).

3. Oganessian, Yu. Ts., Utyonkov, V. K., Lobanov, Yu. V., Abdullin, F. Sh., Polyakov, A. N., Shirokovsky, I. V., Tsyganov, Yu. S., Gulbekian, G. G., Bogomolov, S. L., Mezentsev, A. N., Iliev, S., Subbotin, V. G., Sukhov, A. M., Voinov, A. A., Buklanov, G. V., Subotic, K., Zagrebaev, V. I., Itkis, M. G., Patin, J. B., Moody, K. J., Wild, J. F., Stoyer, M. A., Stoyer, N. J., Shaughnessy, D. A., Kenneally, J. M., and Lougheed, R. W.: Experiments on the synthesis of element 115 in the reaction ${ }^{243} \mathrm{Am}\left({ }^{48} \mathrm{Ca}, x \mathrm{n}\right){ }^{291-x} 115$. Phys. Rev. C 69, 021601(R) (2004).

4. Oganessian, Yu. Ts., Utyonkov, V. K., Dmitriev, S. N., Lobanov, Yu. V., Itkis, M. G., Polyakov, A. N., Tsyganov, Yu. S., Mezentsev, A. N., Yeremin, A. V., Voinov, A. A., Sokol, E. A., Gulbekian, G. G., Bogomolov, S. L., Iliev, S., Subbotin, V. G., 
Sukhov, A. M., Buklanov, G. V., Shishkin, S. V., Chepygin, V. I., Vostokin, G. K., Aksenov, N. V., Hussonnois, M., Subotic, K., Zagrebaev, V. I., Moody, K. J., Patin, J. B., Wild, J. F., Stoyer, M. A., Stoyer, N. J., Shaughnessy, D. A., Kenneally, J. M., Wilk, P. A., Lougheed, R. W., Gäggeler, H. W., Schumann, D., Bruchertseifer, H., and Eichler, R.: Synthesis of elements 115 and 113 in the reaction ${ }^{243} \mathrm{Am}+{ }^{48} \mathrm{Ca}$. Phys. Rev. C 72, 034611 (2005).

5. Dmitriev, S. N., Oganessyan, Yu. Ts., Utyonkov, V. K., Shishkin, S. V., Yeremin, A. V., Lobanov, Yu. V., Tsyganov, Yu. S., Chepygin, V. I., Sokol, E. A., Vostokin, G. K., Aksenov, N. V., Hussonnois, M., Itkis, M. G., Gäggeler, H. W., Schumann, D., Bruchertseifer H., Eichler, R., Shaughnessy, D. A., Wilk, P. A., Kenneally, J. M., Stoyer, M. A. and Wild, J. F.: Chemical identification of dubnium as a decay product of element 115 produced in the reaction ${ }^{48} \mathrm{Ca}+{ }^{243} \mathrm{Am}$. Mendeleev Commun. 15, 1 (2005).

6. Stoyer, N. J., Landrum, J. H., Wilk, P. A., Moody, K. J., Kenneally, J. M., Shaughnessy, D. A., Stoyer, M. A., Wild, J. F., Lougheed, R.W., Dmitriev, S. N., Oganessian, Yu. Ts., Shishkin, S. V., Aksenov, N. V., Tereshatov, E. E., Bozhikov, G. A., Vostokin, G. K., Utyonkov, V. K., and Yeremin, A. A.: Chemical identification of a long-lived isotope of dubnium, a descendant of element 115 . Nucl. Phys. A 787, 388c (2007).

7. Schumann, D., Bruchertseifer, H., Eichler, R., Eichler, B., Gäggeler, H. W., Dmitriev, S. N., Oganessian, Yu. Ts., Utyonkov, V. K., Shishkin, S. V., Yeremin, A. A., Lobanov, Yu. V., Tsyganov, Yu. S., Chepygin, V. I., Sokol, E. A., Vostokin, G. K., Aksenov, N. V., Hussonnois, M., and Itkis, M. G.: Chemical procedure applied for the identification of $\mathrm{Rf} / \mathrm{Db}$ produced in the ${ }^{48} \mathrm{Ca}+{ }^{243} \mathrm{Am}$ reaction. Radiochim. Acta 93, 727 (2005).

8. Wilk, P. A., Landrum, J. H., Shaughnessy, D. A., Kenneally, J. M., Stoyer, N. J., Stoyer, M. A., Moody, K. J., Aksenov, N. V., Bozhikov, G. A., Tereshatov, E. E., Vostokin, G. K., Shishkin, S. V., Dmitriev, S. N.: Separation of group five elements by reversed-phase chromatography. J. Radioanal. Nucl. Chem. 275, 651 (2008).

9. Dressler, R., Eichler, R., Schumann, D., Shishkin, S. V.: Long-term $\alpha$ - and spontaneous fission measurement of a $\mathrm{Rf} / \mathrm{Db}$ sample chemically prepared in a ${ }^{48} \mathrm{Ca}$ on ${ }^{243}$ Am experiment. Phys. Rev. C 79, 054605 (2009). 
10. Henderson, R. A., Moody, K. J.: ${ }^{243} \mathrm{Am}+{ }^{48} \mathrm{Ca}$ : A second look at the Rf/Db data set. In: LLNL internal report, LLNL-TR-400981 (https://e-reportsext.1lnl.gov/pdf/357247.pdf) 2008 .

11. Münzenberg, G.: Recent advances in the discovery of transuranium elements. Rep. Prog. Phys. 51, 57 (1988).

12. Siiskonen, T., Huikari, J., Haavisto, T., Bergman, J., Heselius, S.-J., Lill, J.-O., Lönnroth, T., Peräjärvi, K., Vartti, V.-P.: Excitation functions for proton-induced reactions on natural hafnium: Production of ${ }^{177} \mathrm{Lu}$ for medical use. Nucl. Instr. Meth. Phys. Res. B 267, 3500 (2009).

13. Krivan, V.: Instrumental multielement proton activation analysis of high-purity niobium using both $\gamma$-ray and X-ray spectrometry. Anal. Chem. 47, 469 (1975).

14. Uddin, M. S., Khandaker, M. U., Kim, K. S., Lee, Y. S., Lee, M. W., Kim, G. N.: Excitation functions of the proton induced nuclear reactions on natural zirconium. Nucl. Instr. Meth. Phys. Res. B 266, 13 (2008).

15. Khandaker, M. U., Kim, K., Lee, M. W., Kim, K. S., Kim, G. N., Cho, Y. S., Lee, Y. O.: Experimental determination of proton-induced cross-sections on natural zirconium. Appl. Rad. Is. 67, 1341 (2009).

16. Maiti, M., Lahiri S.: Separation of no-carrier-added ${ }^{90} \mathrm{Nb}$ from proton induced natural zirconium target. J. Radioanal. Nucl. Chem. 283, 637 (2010).

17. Tárkányi, F., Takács, S., Szelecsényi, F., Ditrói, F., Hermanne, A., Sonck, M.: Excitation functions of proton induced nuclear reactions on natural tungsten up to 34 MeV. Nucl. Instr. Meth. Phys. Res. B 252, 160 (2006).

18. Tereshatov, E. E., Bruchertseifer, H., Voronyuk, M. G., Starodub, G. Ya., Petrushkin, O. V., Dmitriev, S. N.: Isocratic anion exchange separations of Group V elements. J. Radioanal. Nucl. Chem. 286, 9 (2010).

19. Kim, J. I., Lagally, H., Born, H.-J.: Ion exchange in aqueous and aqueous-organic solvents. Part I. Anion-exchange behaviour of $\mathrm{Zr}, \mathrm{Nb}$, $\mathrm{Ta}$ and $\mathrm{Pa}$ in aqueous $\mathrm{HCl}-\mathrm{HF}$ and in HCl-HF-organic solvent. Anal. Chim. Acta 64, 29 (1973).

20. Caletka, R., Krivan, V.: Anion-exchange behaviour of some elements in $\mathrm{HF}-\mathrm{HCl}$ medium. J. Radioanal. Nucl. Chem. 142, 373 (1990).

21. Firestone, R. B.: Table of Isotopes, 8th ed., Wiley, New York 1996, p. 225. 
22. Faix, W. G., Caletka, R., Krivan, V.: Element distribution coefficients for hydrofluoric acid/nitric acid solutions and the anion exchange resin Dowex 1x8. Anal. Chem. 53, 1719 (1981).

23. Caletka, R., Krivan, V.: Behaviour of 18 elements in $\mathrm{HF}$ and $\mathrm{HF}-\mathrm{NH}_{4} \mathrm{~F}$ media on anion exchanger in various ionic forms. J. Radioanal. Nucl. Chem. 142, 359 (1990).

24. Caletka, R., Hausbeck, R., Krivan, V.: Distribution of niobium and tantalum on Dowex-1 and polyurethane foam in $\mathrm{HF}-\mathrm{H}_{2} \mathrm{SO}_{4}$ and $\mathrm{HF}-\mathrm{HCl}$ medium. J. Radioanal. Nucl. Chem. 131, 343 (1989).

25. Bruchertseifer, H., Gäggeler, H. W., Tereshatov, E. E., Aksenov, N. V., Shishkin, S. V., Bozhikov, G. A., Vostokin, G. K., Starodub, G. Y., Dmitriev, S. N.: Anion exchange separation of $\mathrm{Pa}, \mathrm{Nb}$ and $\mathrm{Ta}$ in aqueous mineralic acid solutions. In: PSI annual report 2006. PSI, Villigen 2007, p. 8.

26. Guseva, L. I., Tikhomirova, G. S.: Ion exchange behavior and separation of actinides in different oxidation state on cation exchangers in dilute solutions of hydrofluoric acid. Radiochemistry 2, 103 (1993).

27. Caletka, R., Krivan, V.: Cation-exchange of 43 elements from hydrofluoric acid solution. Talanta 30, 543 (1983).

28. Marhol, M.: Ion exchangers in analytical chemistry. Part 1. Academia, Prague 1982, p. 264. 